\title{
A Method for Improving Permeability Accuracy of Tight Sandstone Gas Reservoirs Based on Core Data and NMR Logs
}

\author{
Liang Liu $\odot$, Heping Pan *, Chengxiang Deng and Guoshu Huang \\ Hubei Subsurface Multi-Scale Imaging Key Lab, Institute of Geophysics \& Geomatics, \\ China University of Geosciences, Wuhan 430074, China \\ * Correspondence: panpinge@163.com
}

Received: 27 May 2019; Accepted: 23 July 2019; Published: 25 July 2019

\begin{abstract}
Accurate calculation of the permeability of tight sandstone gas reservoirs has been a challenge, due to the enhanced effect of pore structure. Reservoir permeability with the same porosity and different pore structure often varies greatly. The permeability estimated by the traditional core sample regression analysis method has low accuracy, and the nuclear magnetic resonance (NMR) logging method is affected by the hydrocarbon of the reservoir. In this paper, the defined parameter can effectively quantify the difference of pore structure. Based on regression analysis of core measurement data, the model with optimal factor parameters of permeability calculation is established. This method combines the advantages of empirical models and pore structure models in calculating permeability. The results show that the method can effectively improve the accuracy of permeability. It has been successfully applied to the tight sandstone gas reservoir of He3 member in Hangjinqi area, Ordos Basin, China. Compared with other permeability theoretical models, it provides a more accurate and practical method for calculating permeability.
\end{abstract}

Keywords: permeability; pore structure; optimal parameter; tight sandstone gas reservoirs

\section{Introduction}

Permeability is an important petrophysical property in reservoir evaluation [1]. It is not only related to porosity, but also to other factors such as pore structure. For homogeneous porous media, Kozeny proposed a formula based on capillary theory [2]. Later, Carman developed this formula [3], namely the Kozeny-Carman formula. Since the specific surface area cannot be directly obtained from logging data, the application of Kozeny-Carman formula is limited. Timur suggested that the permeability is controlled by the irreducible water saturation [4]. The irreducible water saturation can reflect the change of the pore structure to a certain extent, but the premise also needs to accurately calculate the irreducible water saturation. The effect of pore coordination number on permeability has attracted much attention. The pore connectivity is the main factor affecting permeability [5]. In order to predict reliable permeability, in addition to porosity, other parameters such as pore shape, pore size, and distribution must be considered [6].

The traditional method of estimating permeability is to obtain empirical formulas by regression analysis of core samples [7]. Permeability and porosity of high porosity reservoirs are often well correlated. However, for unconventional reservoirs with low permeability, the influence of pore structure becomes dominant [8,9]. Analysis of various pore sizes and their contribution to seepage capacity is an effective method for calculating permeability [10]. The reservoir quality index (RQI) and the flow zone indicator (FZI) [11] are the primary and important parameters of hydraulic flow unit theory used for pore structure evaluation and formation classification in the presence of strong 
heterogeneity. Nuclear magnetic resonance (NMR) measurement is an important method for studying the pore structures of reservoirs, as it is a fast method in estimating the porosity, permeability, fluid, and pore size distributions. The Timur-Coates and Schlumberger's permeability calculation models (SDR) are two classical models for the calculation of permeability by NMR logs, both of which take the effects of pore structure into account. Therefore, the estimation accuracy is higher than conventional logs. However, in terms of application effect, reservoirs with high porosity and permeability are better than those with low porosity and permeability [12]. Some scholars have improved methods for calculating unconventional reservoir permeability by NMR, such as capillary pressure combined with NMR logs method [13], and calculating Pore-throat characteristic parameters based on NMR logging data [14]. These methods require a lot of mercury injection experiments. The principle of the artificial neural network is also applied to predict reservoir permeability $[15,16]$. Zhao et al. [17] calculated shale permeability by mineral content from geochemical logs.

In this paper, we use the core data for regression analysis to determine the variable parameters of the pore structure quality index and NMR logging parameters, and establish a workflow to accurately calculate the permeability. It is an effective and practical method to estimate permeability more accurately for tight sandstone gas production. In addition, the permeability results calculated by different equations were compared and analyzed to find the reasons for the differences, and the applicable conditions of the permeability estimation equation were also discussed.

\section{Data}

\subsection{Study Area}

The Ordos Basin is located in the central and western regions of China. The total area of the basin is about $330,000 \mathrm{~km}^{2}$, and the Ordos Basin contains abundant oil and gas resources [18]. Figure $1 \mathrm{~b}$ shows the Hangjinqi research area located in the northwest of Ordos Basin [19].

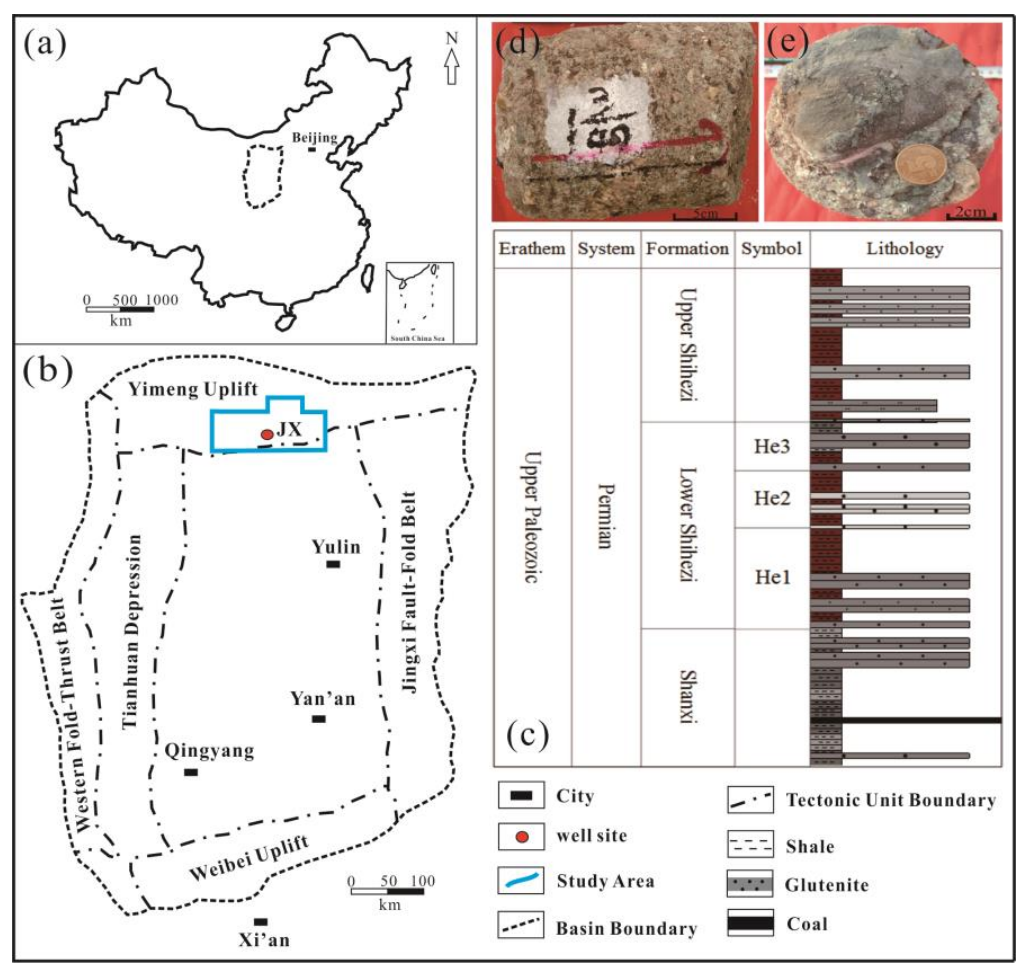

Figure 1. (a) Scope of Ordos Basin in China; (b) location of Hanginqi area in Ordos Basin; (c) stratigraphic sequence; (d) glutenite in the He3 member of the JX well, depth 3047.65-3047.77 m; (e) glutenite in the He3 member of the JX well, depth 3053.42-3053.68 m. 
The Permian Lower Shihezi Formation is the main gas-bearing formation in the Hangjinqi area, with a thickness of about $130 \mathrm{~m}$. The Lower Shihezi Formation is mainly divided into He1, He2, and He3 members from bottom to top [20]. There is an unconventional tight sandstone gas reservoir in the middle of the He3 member. Its lithology is mainly glutenite. The reservoir has a variety of pore structures and low permeability. Since the He3 is the main -gas-producing member in the study area [21], this paper mainly discusses the permeability estimation method based on the data of the He3 member reservoir of Lower Shihezi Formation.

\subsection{Well logs and Core Data}

Well logs data can effectively evaluate various parameters of reservoir rock physics. The JX well is the latest borehole in the study area. It can be used to demonstrate the reliability of the permeability calculation formula obtained from the previous core and well logs data. From the study area, conventional logs data such as lithology logging (GR), resistivity logging (RT), natural potential (SP), and NMR logging etc. are collected. These data can effectively identify tight sandstone gas reservoirs.

The data of 200 core samples in the reservoir of the He3 member are collected. These data show that the porosity of the He3 member is from $3.93 \%$ to $18.87 \%$, an average of $11.53 \%$. The permeability is $0.12 \mathrm{mD}$ to $4.495 \mathrm{mD}$, a mean of $0.955 \mathrm{mD}$. Therefore, the He3 member reservoir of the study area belongs to the tight sandstone reservoir [22]. These data appear in Figure 2a instead of in the table of this paper. $21 \mathrm{NMR}$ core samples from the reservoir of the He3 member are collected and listed in Table 1. Table 2 lists the various types of equations obtained by regression analysis based on the data in Table 1. The data of 13 core samples from the He3 reservoir in the JX well are listed in Table 3.

Table 1. Core physical property parameters obtained by nuclear magnetic resonance (NMR) experiments.

\begin{tabular}{|c|c|c|c|c|c|c|c|}
\hline \multirow{2}{*}{ No. } & $\Phi$-Helium & K-Helium & $\Phi-N M R$ & Swi & $\mathrm{T}_{2}$ cutoff & MFFI & BVI \\
\hline & $(\%)$ & $(\mathrm{mD})$ & $(\%)$ & $(\%)$ & (ms) & $(\%)$ & $(\%)$ \\
\hline 1 & 10.8 & 0.620 & 10.6 & 49.1 & 14.28 & 5.5 & 5.3 \\
\hline 2 & 15.1 & 1.819 & 14.6 & 34.4 & 14.60 & 9.9 & 5.2 \\
\hline 3 & 13.4 & 2.080 & 13.2 & 31.9 & 18.51 & 9.1 & 4.3 \\
\hline 4 & 14.1 & 1.423 & 13.9 & 36.6 & 13.34 & 8.9 & 5.2 \\
\hline 5 & 13.9 & 1.054 & 13.4 & 32.2 & 9.66 & 9.4 & 4.5 \\
\hline 6 & 13.7 & 1.269 & 13.5 & 29.0 & 11.03 & 9.7 & 4.0 \\
\hline 7 & 15.4 & 4.625 & 14.7 & 22.8 & 9.50 & 11.9 & 3.5 \\
\hline 8 & 11.7 & 4.195 & 11.4 & 26.9 & 11.68 & 8.5 & 3.2 \\
\hline 9 & 8.4 & 0.195 & 8.2 & 41.5 & 14.22 & 4.9 & 3.5 \\
\hline 10 & 10.3 & 0.992 & 10.1 & 28.7 & 7.05 & 7.3 & 3.0 \\
\hline 11 & 7.2 & 0.522 & 7.1 & 46.0 & 13.08 & 3.9 & 3.3 \\
\hline 12 & 11.9 & 0.606 & 11.5 & 29.9 & 15.25 & 8.3 & 3.6 \\
\hline 13 & 8.6 & 0.306 & 8.2 & 34.8 & 6.10 & 5.6 & 3.0 \\
\hline 14 & 11.1 & 0.565 & 10.9 & 38.2 & 8.77 & 6.9 & 4.2 \\
\hline 15 & 3.3 & 0.161 & 3.5 & 47.8 & 7.27 & 1.7 & 1.6 \\
\hline 16 & 9.8 & 2.656 & 9.6 & 19.2 & 22.92 & 7.9 & 1.9 \\
\hline 17 & 7.8 & 1.600 & 7.8 & 20.7 & 14.48 & 6.2 & 1.6 \\
\hline 18 & 7.5 & 0.206 & 7.0 & 35.0 & 15.04 & 4.9 & 2.6 \\
\hline 19 & 15.3 & 10.879 & 14.5 & 6.4 & 22.59 & 14.3 & 1.0 \\
\hline 20 & 13.8 & 8.250 & 13.5 & 7.1 & 19.75 & 12.8 & 1.0 \\
\hline 21 & 10.4 & 7.350 & 9.7 & 10.0 & 16.38 & 9.4 & 1.0 \\
\hline
\end{tabular}

$\mathrm{Swi}=\mathrm{BVI} /(\mathrm{MFFI}+\mathrm{BVI})$. If the Swi value increases, it means that the volume of the non-flowable fluid increases in the rock, resulting in a decrease in permeability. 
Table 2. The highest correlation coefficient of various equations model and the values of $a$ and $b$ involved are when $m$ is 1.02 and $n$ is 0.03 .

\begin{tabular}{ccccc}
\hline Type & Equation & $\boldsymbol{a}$ & $\boldsymbol{b}$ & $\mathbf{R}^{\mathbf{2}}$ \\
\hline Polynomial & $\mathrm{y}=-0.0006 \mathrm{x}^{2}+0.1629 \mathrm{x}-0.632$ & 1.82 & 0.90 & 0.9236 \\
Linear & $\mathrm{y}=7.0798 \mathrm{x}-8.7781$ & 0.35 & 0.26 & 0.8874 \\
Logarithmic & $\mathrm{y}=18.464 \ln (\mathrm{x})-1.3917$ & 0.20 & 0.19 & 0.8440 \\
Power & $\mathrm{y}=0.0397 \mathrm{x}^{1.2803}$ & 1.70 & 0.70 & 0.8169 \\
Exponential & $\mathrm{y}=0.0666 \mathrm{e}^{0.5298 \mathrm{x}}$ & 0.90 & 0.16 & 0.8019 \\
\hline
\end{tabular}

Table 3. The result of permeability calculation of the JX well and its correlation coefficient with core sample permeability, where K_Equations (10) and (11) represents the permeability calculated by Equations (10) and (11).

\begin{tabular}{ccccccc}
\hline \multirow{2}{*}{ No. } & Depth & K_core & K_NMR & K_Equation (1) & K_Equation (2) & $\begin{array}{c}\text { K_Equations (10) and } \\
\text { (11) }\end{array}$ \\
\cline { 2 - 7 } & $\mathbf{( m )}$ & $\mathbf{( m D )}$ & $\mathbf{( m D )}$ & $\mathbf{( m D )}$ & $\mathbf{( m D )}$ & $\mathbf{( m D )}$ \\
\hline 1 & 3046.35 & 0.0910 & 0.0014 & 0.5776 & 0.0797 & 0.0789 \\
\hline 2 & 3046.72 & 0.0604 & 0.0012 & 0.6603 & 0.0421 & 0.0402 \\
\hline 4 & 3047.25 & 0.0162 & 0.0010 & 0.7973 & 0.0232 & 0.0042 \\
\hline 5 & 3047.55 & 0.0261 & 0.0035 & 1.0892 & 0.0190 & 0.0029 \\
\hline 6 & 3049.56 & 0.2625 & 0.0246 & 1.3989 & 0.1892 & 0.1615 \\
\hline 7 & 3050.05 & 0.4431 & 0.0325 & 1.0486 & 0.2690 & 0.2570 \\
\hline 8 & 3053.05 & 0.7330 & 0.1245 & 0.6313 & 0.9260 & 0.2233 \\
\hline 9 & 3053.15 & 0.9921 & 0.1216 & 0.6466 & 1.3298 & 0.9357 \\
\hline 10 & 3053.34 & 1.9752 & 0.1247 & 0.6533 & 1.9686 & 1.3375 \\
\hline 11 & 3053.82 & 2.1580 & 0.1490 & 0.6651 & 1.9212 & 1.9340 \\
\hline 12 & 3054.13 & 1.0473 & 0.1088 & 0.6589 & 1.7083 & 1.7154 \\
\hline 13 & 3054.45 & 0.9310 & 0.0806 & 0.7757 & 0.6505 & 0.6550 \\
\hline Correlation coefficient & 0.8959 & 0.4019 & 0.9419 & 0.9418 \\
\hline
\end{tabular}
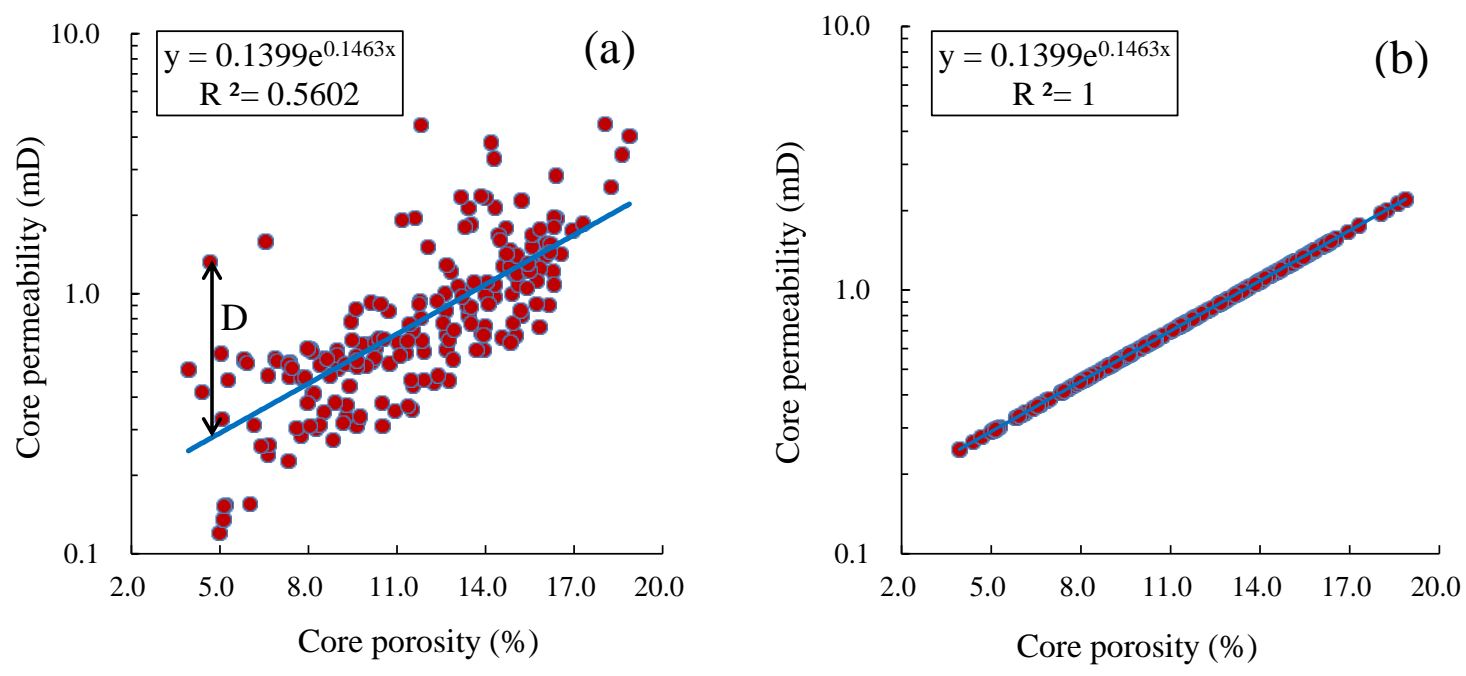

Figure 2. The cross-plot with 200 core samples: (a) Core samples, and (b) samples that eliminate reservoir quality index differences using trend lines as a standard. 


\section{Methodology}

\subsection{Regression Analysis}

Figure 2a shows the regression analysis of core samples from the He3 member of Lower Shihezi Formation, and the empirical relationship between porosity and permeability is obtained.

$$
\mathrm{K}=0.1399 \mathrm{e}^{0.1463 \phi} \quad\left(\mathrm{R}^{2}=0.5602\right)
$$

Equation (1) is exponential but the correlation is only 0.5602. In Figure 2a, this exponential line can be regarded as a mainstream empirical relationship trend that solves the permeability by porosity in the He3 member reservoir of the study area.

The $\mathrm{D}$ is the difference between core permeability and the prediction value by Equation (1) in Figure 2a. The reservoir of the He3 member is a tight sandstone gas reservoir without fracture. When the lithology of the reservoir is the same, the $\mathrm{D}$ value can be considered to be caused by the difference in the shape, size, and distribution of rock pore and throat. These factors can usually be defined as the pore structure [23]. We define $\mathrm{D}$ as the pore structure influence factor, which is closely related to reservoir quality index [24,25]. It is a key correction parameter for calculating accurate permeability.

The permeability in Figure $2 b$ is obtained by using the core porosity data of Figure $2 a$ as the independent variable calculated by Equation (1). As shown in Figure $2 b$, if the influencing factors of the reservoir quality index are eliminated, each depth point in the reservoir has the same pore structure, and the permeability can be accurately determined from the porosity. However, the reality is that porosity and reservoir quality index together determine permeability, especially in unconventional tight gas reservoirs. Therefore, more accurate permeability can be obtained from Equation (2) if the D value can be accurately calculated.

$$
\mathrm{K}=0.1399 \mathrm{e}^{0.1463 \phi}+\mathrm{D}
$$

\subsection{Value Solution}

Kozeny and Carman proposed a formula for calculating the permeability by capillary theory [3], which is expressed as:

$$
\mathrm{K}=\frac{\phi^{3}}{(1-\phi)^{2}} \cdot \frac{1}{\mathrm{~F}_{\mathrm{s}} \tau^{2} \mathrm{~S}_{\mathrm{gv}}{ }^{2}}
$$

The reservoir quality index parameter can be defined by deducing Equation $(3)[7,26]$ :

$$
\mathrm{RQI}=0.0314 \sqrt{\frac{\mathrm{K}}{\phi}}
$$

To study the difference of the reservoir quality index, and to deduce a precise relationship between the reservoir quality index difference and $\mathrm{D}$ in the study area, the reservoir quality index parameter can be deduced as:

$$
\mathrm{RQI}=\frac{\mathrm{K}^{m}}{\phi^{n}}
$$

where $m$ and $n$ denote permeability and porosity indices greater than zero, respectively. The two parameters can be changed independently. Thus, the formula for solving the $\mathrm{D}$ value can be expressed as:

$$
\begin{gathered}
\Delta \mathrm{RQI}=\frac{\mathrm{K}^{m}}{\phi^{n}}-\frac{\mathrm{K}_{\mathrm{s}}^{m}}{\phi^{n}} \\
\mathrm{D}=f(\Delta \mathrm{RQI})=f\left(\frac{\mathrm{K}^{m}-\mathrm{K}_{\mathrm{s}}^{m}}{\phi^{n}}\right)
\end{gathered}
$$


where $K_{s}$ is the permeability calculated by Equation (1). The key factor for the establishment of Equation (7) is to find the appropriate $m$ and $n$ values. It can be obtained by fitting analysis of $\triangle \mathrm{RQI}$ and D.

In Equation (5), RQI represents the reservoir quality index and is positively correlated with the reservoir pore structure. NMR methods can effectively identify pore structure characteristics. A total of 21 NMR experimental samples were collected in Table 1 to study the relationship between the parameters of the NMR $\mathrm{T}_{2}$ distributions and the reservoir quality index. The $\mathrm{NMR}_{2}$ distributions of sample No. 1 are shown in Figure 3a. After centrifugation, the peak of the $T_{2}$ spectrum shifts to the left and the area decreases. The $T_{2}$ cutoff value was obtained experimentally, which is the standard for distinguishing between irreducible fluids and mobile fluids [27-31]. Therefore, movable and irreducible porosity can be obtained in Figure $3 \mathrm{~b}$. Movable porosity and irreducible porosity can be understood as connected porosity and unconnected porosity or effective porosity and ineffective porosity, respectively. The ratio of movable porosity to irreducible porosity can be linked to the reservoir quality index to find a way to characterize the reservoir quality index using parameters obtained by NMR. An equation can be established between them, which can be expressed as:

$$
\mathrm{RQI}=\frac{\mathrm{K}^{m}}{\phi^{n}}=f\left(\frac{\mathrm{MFFI}^{a}}{\mathrm{BVI}^{b}}\right)
$$

where MFFI is movable porosity, BVI is irreducible porosity, and $a$ and $b$ represent the indices of MFFI and BVI, respectively.

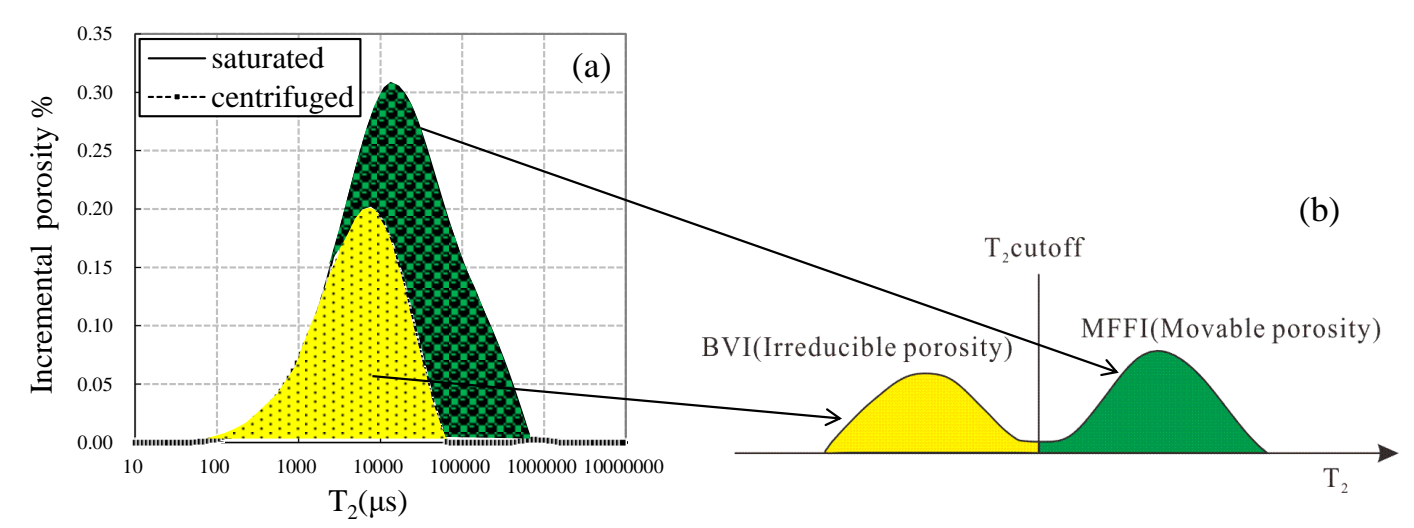

Figure 3. (a) The NMR $T_{2}$ distributions for sample No. 1, and (b) movable (green area) and irreducible (yellow area) porosity of sample No. 1.

\subsection{Calculation Procedure}

The method of estimating permeability from core and NMR data includes the following steps.

(1) An empirical equation similar to Equation (1) is obtained by fitting the core data.

(2) The value of $\mathrm{D}$ is obtained by subtracting the permeability by Equation (1) from the permeability of all core samples at the same porosity. The initial values of $m$ and $n$ are given arbitrarily, and the $\triangle \mathrm{RQI}$ values are calculated by Equation (6).

(3) Regression analysis using $\Delta \mathrm{RQI}$ and $\mathrm{D}$ values, with the $m$ and $n$ values changing, the optimum $m$ and $n$ values are determined when the correlation coefficient of polynomial function is the highest.

(4) Regression analysis using the independent and dependent variables of Equation (8), when the optimized $m$ and $n$ values remain constant. The initial values of $a$ and $b$ are given arbitrarily, with the $a$ and $b$ values changing, the optimum $a$ and $b$ values are determined when the correlation coefficient of the power function is the highest.

(5) When the optimum values of $a, b, m$, and $n$ are determined, Equation (8) can be derived from Equation (7), D can be calculated from Equation (7), and more accurate permeability can be obtained from Equation (2). 


\section{Result and Discussion}

\subsection{Parameter Prediction and Model Establishment}

Based on 200 core samples, all the D values are calculated with core porosity based on the principles shown in Figure 2. After setting the initial values of $m$ and $n$ (both set to 0.5 in this paper), the value of RQI is calculated by Equation (6). Polynomial regression analysis of the calculated $\Delta \mathrm{RQI}$ and $\mathrm{D}$ values and observing the correlation coefficient as the $m$ and $n$ values change. The results of partial regression analysis are shown in Figure 4. Especially when $m$ and $n$ are both 0.5 , the RQI equation shown by Equation (5) is similar to Equation (4). However, the correlation coefficient is 0.8447. The highest correlation coefficient is determined by the combination of $m$ and $n$ values, rather than monotonic change with increasing or decreasing $m$ or $n$ values. In this paper, when the correlation coefficient is the highest, the optimal value $m$ is 1.02 , and $n$ is 0.03 . As shown in Figure 5 , the equation of Equation (7) can be expressed as:

$$
\mathrm{D}=-0.0055\left(\frac{\mathrm{K}^{1.02}-\mathrm{K}_{\mathrm{s}}^{1.02}}{\phi^{0.03}}\right)^{2}+1.0572\left(\frac{\mathrm{K}^{1.02}-\mathrm{K}_{\mathrm{s}}^{1.02}}{\phi^{0.03}}\right)-0.0007 \quad\left(\mathrm{R}^{2}=1\right)
$$

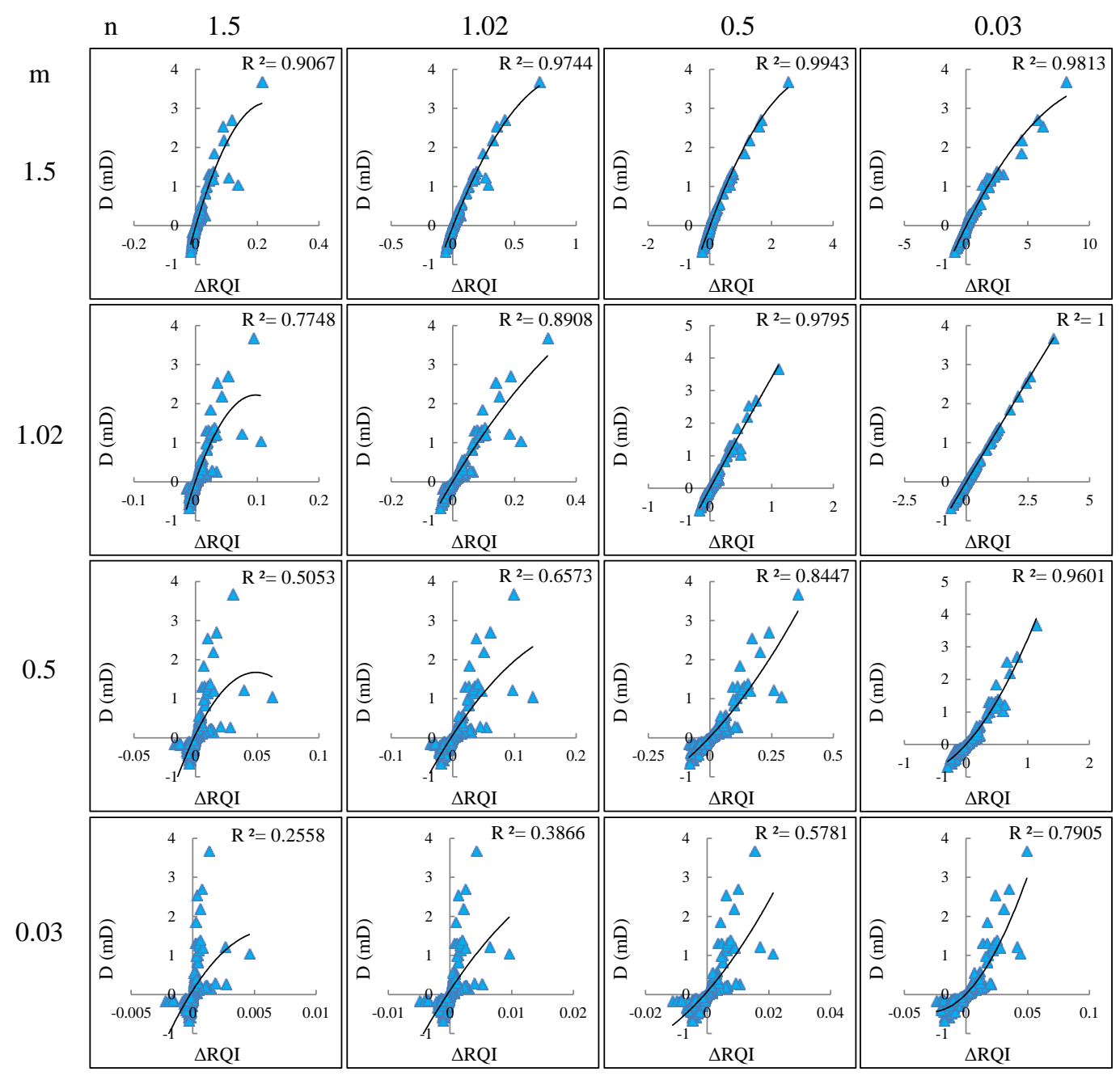

Figure 4. The partial statistical results of the correlation between the D value and the $\triangle \mathrm{RQI}$ (reservoir quality index), as the $m$ and $n$ values change. 


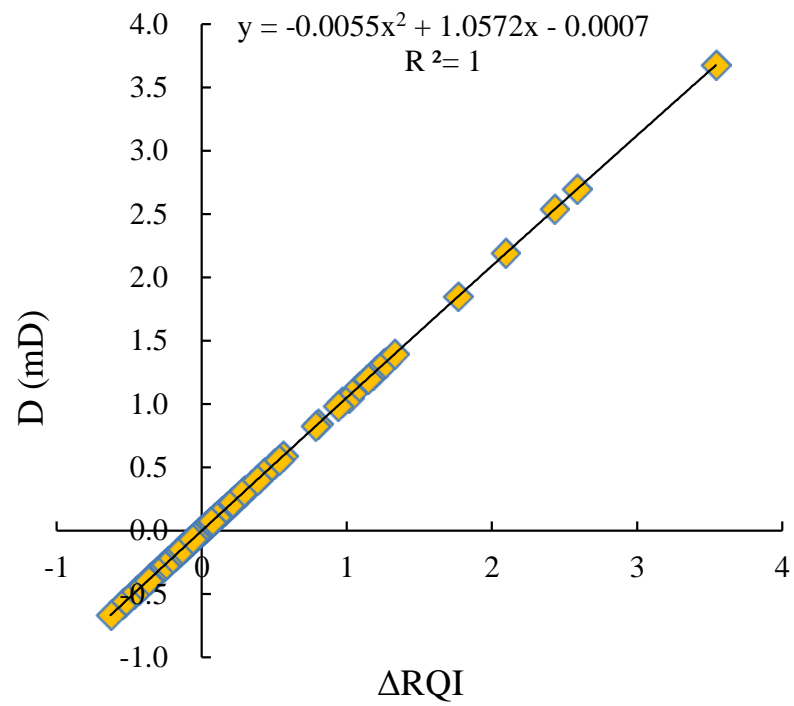

Figure 5. The cross-plot between $\mathrm{D}$ and $\Delta \mathrm{RQI}$. The highest polynomial correlation coefficient is 1 when $m$ is 1.02 and $n$ is 0.03 .

Keeping $m$ at 1.02 and $n$ at 0.03 , regression analysis was carried out with the independent and dependent variables of Equation (8). The data involved in the regression analysis were derived from the helium porosity, helium permeability, movable pore volume, and irreducible pore volume in Table 1 . Figure 6 shows the partial polynomial statistical results. When the highest correlation coefficient of polynomial regression analysis is 0.9236 , the optimal value $a$ is 1.82 and $b$ is 0.9. As shown in Figure 7, the Equation (8) can be expressed as:

$$
\mathrm{RQI}=\frac{\mathrm{K}^{1.02}}{\phi^{0.03}}=-0.0006\left(\frac{\mathrm{MFFI}^{1.82}}{\mathrm{BVI}^{0.9}}\right)^{2}+0.1629\left(\frac{\mathrm{MFFI}^{1.82}}{\mathrm{BVI}^{0.9}}\right)-0.632 \quad\left(\mathrm{R}^{2}=0.9236\right)
$$

It is noteworthy that the result calculated by Equation (10) may produce a negative number because it is polynomial regression analysis. However, it is impossible for the reservoir quality index to be negative, so we add other forms of regression analysis equations. Table 2 shows the highest correlation coefficients in various forms, and the associated $a$ and $b$ values. Since polynomial, linear, and logarithmic equations are likely to produce negative numbers after calculation, the power function equation is chosen as the supplementary calculation method of Equation (10), which can be expressed as:

$$
\mathrm{RQI}=\frac{\mathrm{K}^{1.02}}{\phi^{0.03}}=0.0397\left(\frac{\mathrm{MFFI}^{1.7}}{\mathrm{BVI}^{0.7}}\right)^{1.2803} \quad\left(\mathrm{R}^{2}=0.8169\right)
$$

The correlation coefficient of Equation (11) is 0.8169. Although it is not higher than Equation (10), it can effectively avoid negative values. When Equation (10) calculates a negative value, supplement the calculation with Equation (11) and replace the negative value. 
$\mathrm{b}$ 2.5 1.82 0.9 0.5

a
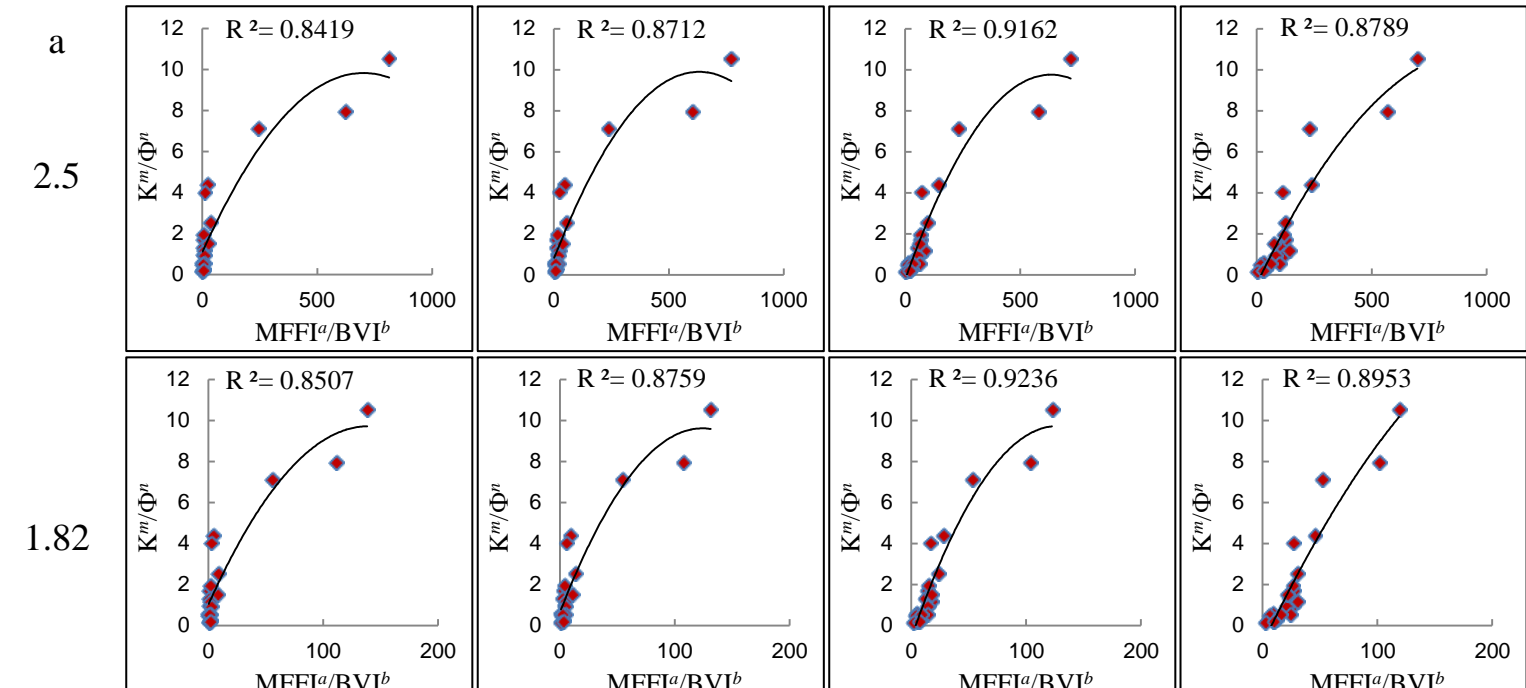

0.9
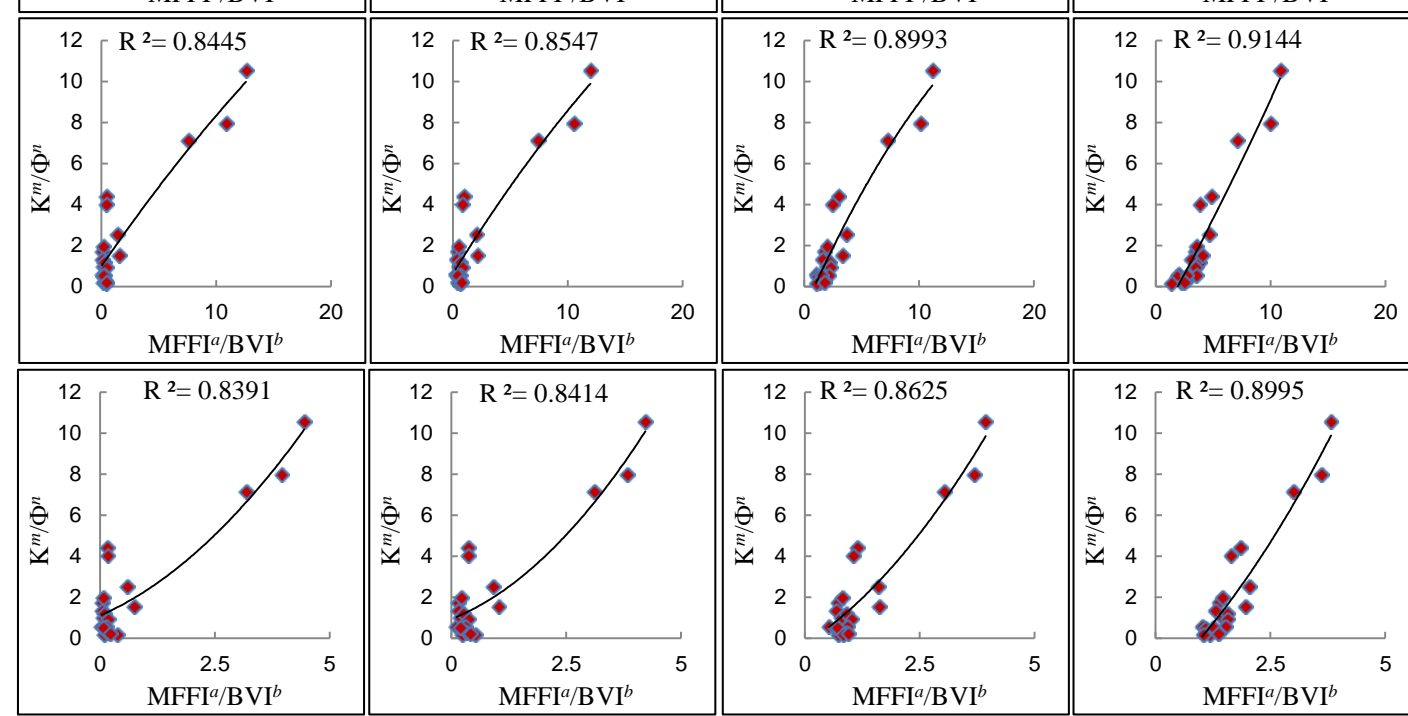

Figure 6. The partial polynomial statistical results of the correlation between the ratio of movable porosity to irreducible porosity, and the RQI as the $a$ and $b$ values change when $m$ is 1.02 and $n$ is 0.03 .

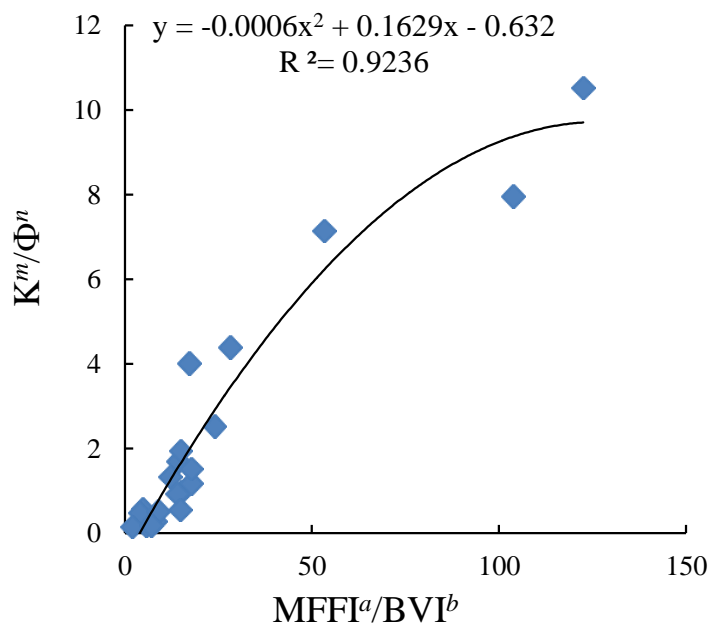

Figure 7. The cross-plot between the ratio of movable pore volume to irreducible pore volume and RQI. $a=1.82 ; b=0.9 ; m=1.02 ; n=0.03$. 


\subsection{Results Evaluation and Analysis}

The JX well is a newly drilled well in the study area. Its core data is not involved in the regression analysis in this paper. We could use this well to verify the validity of the method for calculating permeability. Table 3 lists the correlation coefficients between the core sample of the JX well and the calculated permeability of four models at the same depth. Figure 8 shows the results of the permeability calculation of the He3 member reservoir of the JX well. A depth interval of 3045-3057.4 $\mathrm{m}$ is a tight sandstone gas reservoir. The D value calculated by Equation (9) is listed in Track 9. Core permeability and the results of calculating the permeability using four equations are listed in Track 10.

In Figure 8, the blue curve is the permeability calculated by Equation (2). It is closest to the core sample values, whose correlation is 0.9419 . The black curve is the permeability calculated by Equation (1). Its correlation is 0.4019 because there is no additional D value. The green curve is the permeability calculated by Timur-Coates model with NMR logs. Although the correlation coefficient is higher than Equation (1) with 0.8959 , its permeability is generally lower than core measurements.

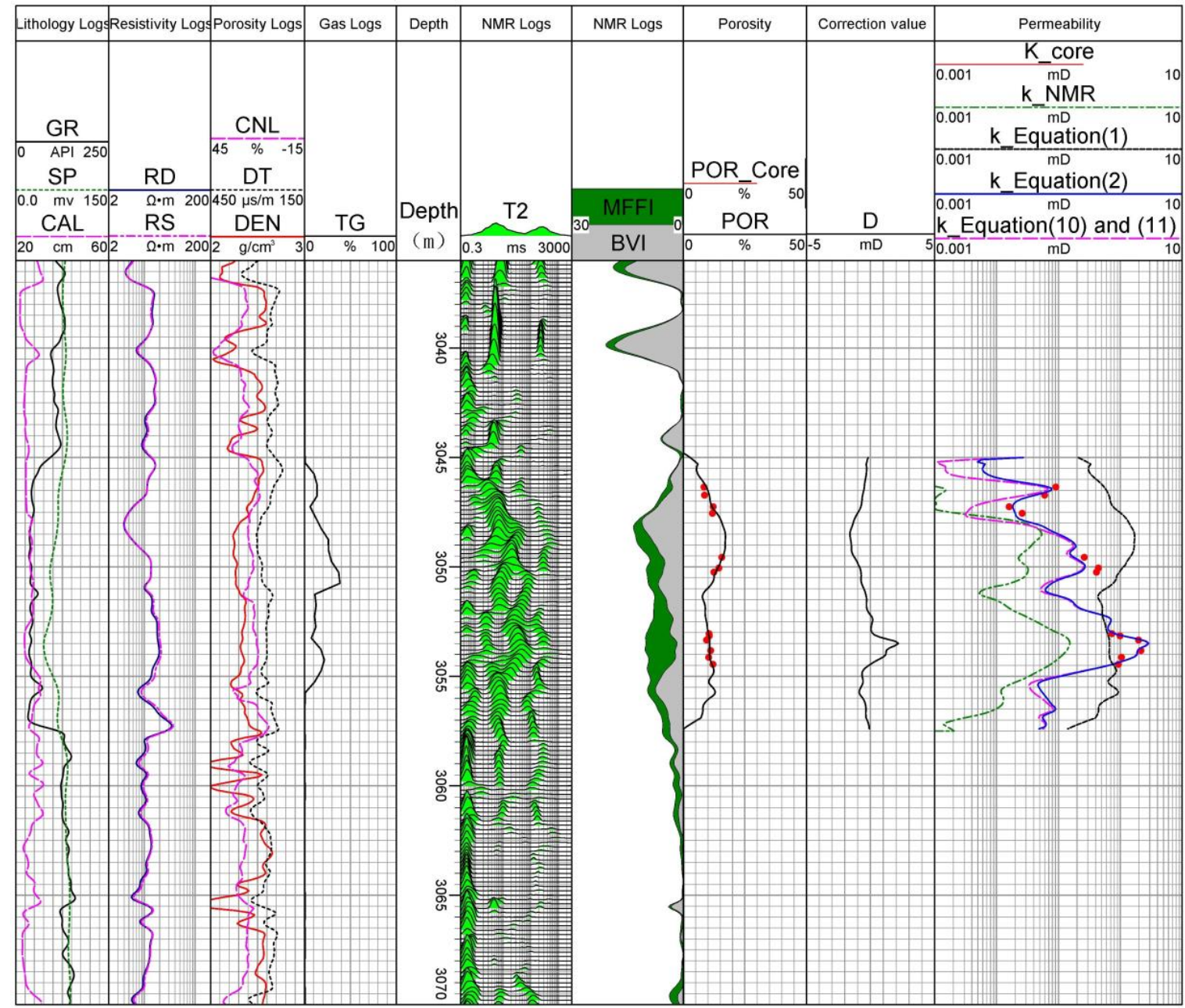

Figure 8. The results of permeability calculation of the JX well. K_core represents core sample permeability; K_NMR represents permeability calculated by NMR logs; K_Equation (1) represents permeability calculated by Equation (1); K_Equation (2) represents permeability calculated by Equation (2); and K_Equations (10) and (11) represents permeability calculated by Equations (10) and (11) - that is, when the calculation results of both are positive, the calculation result of Equation (10) is selected, and when Equation (10) calculates a negative value, it is replaced by the result of Equation (11).

In the upper part of the reservoir at 3045-3051 m, the permeability value obtained from Equation (1) is larger than the lower part of the reservoir in Track 10, because the permeability calculated by 
Equation (1) varies with porosity, as it monotonically increases or decreases. The permeability values calculated by the NMR logs are lower than these core samples. There are two main factors; the first is that NMR logs can effectively identify pore structure. In Track 7, the upper part of the reservoir is high in total porosity but mainly due to the larger bulk volume irreducible, which affects the permeability of the reservoir [32-35]. The second is that the permeability obtained by NMR logs is affected by reservoir gas content [36-38], and the calculated permeability decreases with the increase of the gas content in the reservoir. The total hydrocarbon curve of gas logs is shown in Track 4. It is derived from mud logging data and represents the true gas content in the reservoir. The total hydrocarbon curve indicates that the gas content in the upper part of the reservoir is larger than that the lower part, and the maximum gas content is $38.5 \%$. Therefore, the permeability value calculated by NMR logs in the upper part of the reservoir is more affected by the gas content than the lower part. The permeability calculated by Equation (2) is closer to the core sample, but it is reduced by the influence of reservoir gas bearing property.

In the lower part of the reservoir at 3051-3057.4 m, the permeability calculated by Equation (1) decreases as the porosity decreases. The calculated permeability is larger than the upper part of the reservoir by NMR logs, due to the fact that although the porosity is smaller than the upper part of the reservoir, the movable volume is larger. The permeability of core samples is the closest to that calculated by Equation (2), which proves the validity of the permeability estimation method in this paper.

The method for accurately calculating the permeability shown in this paper is applicable to gas well exploration and development areas with core physical property analysis data and NMR logs data. It is only applicable to the calculation of reservoir matrix permeability. In fractured formations such as shale, carbonate, and sandstone of various grain sizes with fractures, where the fractures change the flow characteristics of the formation fluid, the method in this paper cannot effectively predict the permeability. The premise of obtaining permeability by the method in this paper is to calculate the porosity. There are many methods to obtain porosity accurately, but there is not much discussion in this paper.

It is remarkable that the permeability value can also be calculated directly by Equations (10) and (11) when the reservoir parameters $a$ and $b$ are determined. In theory, when the reservoir contains no hydrocarbons, the permeability values calculated by the two methods should be almost the same. However, when the reservoir contains hydrocarbons, the accuracy of the calculations of Equations (10) and (11) should be reduced because the NMR logs are affected, and the degree of this reduction is unpredictable. Equation (2) consists of two parts; one is the empirical relationship of the core sample, and the other is the correction based on the pore structure factor. Therefore, Equation (2) can offset some of the error rates caused by hydrocarbons to some extent, to ensure the reliability of the calculated permeability. The results calculated by Equations (10) and (11) are shown in Track 10. Since Equations (10) and (11) are affected by NMR logs, the value at the low permeability is lower than the value calculated by Equation (2).

In fact, many scholars have already figured out the impact of hydrocarbons on NMR logs [39-41], but so far, there is no single very effective way to completely eliminate them. The direction we will study in the future is to find an effective way to minimize the impact of hydrocarbons on various geophysical logging methods. If this method is discovered, the accuracy of reservoir permeability will be further improved.

In addition, it should be noted that sedimentary characteristics determine the physical properties of the rock. Porosity, permeability, and pore structure vary from formation-to-formation. Therefore, if the method in this paper is to be applied to other formations, the $a, b, m$, and $n$ values must be analyzed separately to ensure its accuracy. 


\section{Conclusions}

In this paper, the prediction method for permeability of tight sandstone gas reservoirs was studied. This method calculates the permeability using equations with parameters $m, n, a$, and $b$, which combine the advantages of core samples and NMR logs. The empirical nature and applicability of these parameters are attributed to the regression analysis of a large number of core samples from the He3 member reservoir in the study area. The permeability calculation model with optimization $m, n$, $a$, and $b$ is applied to the JX well. The results show that they can effectively improve the calculation accuracy of the permeability. The permeability results calculated by NMR logging were also compared and analyzed. The results show that the method in this paper improves the accuracy of permeability by reducing the influence of hydrocarbon in formation.

Author Contributions: Conception of the paper, H.P.; methodology, L.L. and G.H.; computer analyses, L.L. and C.D.; and writing of the paper, L.L.

Funding: This research was funded by National Key Research and Development Program of China, grant number 2017YFC0601504, 2017YFC0601500; National Nature Science Foundation of China, grant number 41804097. And the APC was funded by 2017YFC0601504, 2017YFC0601500.

Acknowledgments: The authors gratefully appreciate the financial support from the National Key Research and Development Program of China (2017YFC0601504, 2017YFC0601500) and the National Nature Science Foundation of China (41804097). We also acknowledge the editors and reviewers for their constructive suggestions and comments.

Conflicts of Interest: The authors declare no conflicts of interest.

\section{Nomenclature}

\begin{tabular}{|c|c|}
\hline GR & Natural gamma-ray logging, API \\
\hline SP & Spontaneous-potential logging, mv \\
\hline CAL & Borehole diameter, $\mathrm{cm}$ \\
\hline $\mathrm{RD}$ & Deep lateral resistivity, $\Omega . m$ \\
\hline RS & Shallow lateral resistivity, $\Omega . m$ \\
\hline CNL & Compensated neutron logging, $\%$ \\
\hline DT & Acoustic transit time, $\mu \mathrm{s} / \mathrm{m}$ \\
\hline DEN & Density logs, $\mathrm{g} / \mathrm{cm}^{3}$ \\
\hline TG & Total hydrocarbon content, $\%$ \\
\hline $\mathrm{T}_{2}$ & NMR transverse relaxation time, ms \\
\hline BVI & Bulk volume irreducible, $\%$ \\
\hline MFFI & Bulk volume moveable, \% \\
\hline$\Phi$ & Porosity, \% \\
\hline POR_core & Porosity obtained from core analysis, $\%$ \\
\hline Fs & shape factor \\
\hline$\tau$ & tortuosity \\
\hline$S_{\mathrm{gv}}$ & surface area per unit grain volume, $\mu \mathrm{m}^{-1}$ \\
\hline $\mathrm{F}_{\mathrm{s}} \tau^{2}$ & Kozeny constant \\
\hline K & Permeability, mD \\
\hline K_core & Permeability obtained from core analysis, $\mathrm{mD}$ \\
\hline K_NMR & Permeability obtained by NMR logs, mD \\
\hline Swi & Irreducible water saturation, $\%$ \\
\hline
\end{tabular}

\section{References}

1. Shen, B.; Wu, D.; Wang, Z.H. A new method for permeability estimation from conventional well logs in glutenite reservoirs. J. Geophys. Eng. 2017, 14, 1268-1274. [CrossRef]

2. Hereit, F.; Polasek, P. Methodology for Evaluating and Monitoring of Waterworks Performance Efficiency-Part 2: Test of Filterability. Adv. Chem. Eng. Sci. 2014, 4, 470-482. [CrossRef]

3. Carman, P.C. Fluid flow through granular beds. Trans. Inst. Chem. Eng. 1937, 15, 150-166. [CrossRef] 
4. Timur, A. An investigation of permeability, porosity, and residual water saturation relationships. In Proceedings of the SPWLA 9th Annual Logging Symposium, New Orleans, LA, USA, 23-26 June 1968.

5. Henderson, N.; Brêttas, J.C.; Sacco, W.F. A three-parameter Kozeny-Carman generalized equation for fractal porous media. Chem. Eng. Sci. 2010, 65, 4432-4442. [CrossRef]

6. Sun, J.M.; Yan, G.L. Review on Absolute Permeability Model. Well Logging Technol. 2012, 36, 329-334. [CrossRef]

7. Amaefule, J.O.; Altunbay, M.; Tiab, D.; Kersey, D.G.; Keelan, D.K. Enhanced reservoir description: Using core and log data to identify hydraulic (flow) units and predict permeability in uncored intervals/wells. In Proceedings of the SPE Annual Technical Conference and Exhibition, Houston, TX, USA, 3-6 October 1993.

8. Wang, X.J.; Zhang, L.P.; Shi, J.P. Analysis of pore structure characteristics in Hailaer Oilfield. Pet. Geol. Oilfield Dev. Daqing 2007, 26, 91-94. [CrossRef]

9. Liu, X.P.; Hu, X.X. Progress of NMR $\log$ in evaluating reservoir pore structure in the last five years. Prog. Geophys. 2009, 24, 2194-2201. [CrossRef]

10. Ge, X.M.; Fan, Y.R.; Liu, J.Y.; Zhang, L.; Han, Y.J.; Xing, D.H. An improved method for permeability estimation of the bioclastic limestone reservoir based on NMR data. J. Magn. Reson. 2017, 283, 96-109. [CrossRef]

11. Abbaszadeh, M.; Fujii, H.; Fujimoto, F. Permeability prediction by hydraulic flow units-theory and applications. SPE Form. Eval. 1996, 11, 263-271. [CrossRef]

12. Zhu, L.Q.; Zhang, C.; Hu, J.; Wei, Y.; Guo, C. An NMR Logging Permeability Evaluation Method Based on the Representative Elementary Volume Model. Pet. Drill. Tech. 2016, 44, 120-126. [CrossRef]

13. Xiao, L.; Liu, X.P.; Mao, Z.Q. A computation method for reservoir permeability by combining NMR log and capillary pressure data. Acta Pet. Sin. 2009, 30, 100-103.

14. Cheng, Z.G.; Luo, S.C.; Du, Z.W.; Chang, S.; Li, G.L.; Li, H. The method to calculate tight sandstone reservoir permeability using pore throat characteristic parameters. Well Logging Technol. 2014, 38, 185-189. [CrossRef]

15. Shan, J.F.; Ji, Y.L.; Liu, C.Z. Prediction of reservoir permeability with improved artificial neural network principle: Taking the southwest weizhou depression in beibuwan basin as an example. Oil Gas Geol. 2007, 28, 106-109. [CrossRef]

16. Anifowose, F.A.; Labadin, J.; Abdulraheem, A. Ensemble machine learning: An untapped modeling paradigm for petroleum reservoir characterization. J. Pet. Sci. Eng. 2017, 151, 480-487. [CrossRef]

17. Zhao, P.Q.; Cai, J.C.; Huang, Z.H.; Ostadhassan, M.; Ran, F.Q. Estimating permeability of shale gas reservoirs from porosity and rock compositions. Geophysics 2018, 83, MR283-MR294. [CrossRef]

18. Qin, R.D.; Pan, H.P.; Zhao, P.Q.; Deng, C.X.; Peng, L.; Liu, Y.Q.; Kouroura, M. Petrophysical parameters prediction and uncertainty analysis in tight sandstone reservoirs using Bayesian inversion method. J. Nat. Gas Sci. Eng. 2018, 55, 431-443. [CrossRef]

19. Peng, Z.; Zhao, J.H.; Liu, W.H. Using Logging Data to Identify Properties of Paleozoic Sandstone Reservoir Fluid in Hangjinqi Area. Chin. J. Eng. Geophys. 2013, 10, 216-220. [CrossRef]

20. Wang, M.J.; He, D.F.; Bao, H.P.; Lu, R.Q.; Gui, B.L. Upper palaeozoic gas accumulations of the yimeng uplift, ordos basin. Pet. Explor. Dev. 2011, 38, 30-39. [CrossRef]

21. Cao, J.H.; Zhou, W.; Deng, L.Z.; Li, X.H.; Liu, F. Reservoir physical properties and evaluation of lower shihezi formation in hangjinqi area of northern ordos basin. Comput. Tech. Geophys. Geochem. Explor. 2007, 1, 30-34.

22. Zou, C.N.; Zhu, R.K.; Liu, K.Y.; Su, L.; Bai, B.; Zhang, X.X.; Yuan, X.J.; Wang, J.H. Tight gas sandstone reservoirs in china: Characteristics and recognition criteria. J. Pet. Sci. Eng. 2012, 88-89. [CrossRef]

23. Nelson, P.H. Permeability-porosity relationships in sedimentary rocks. Log Anal. 1994, 35. Available online: https://www.onepetro.org/journal-paper/SPWLA-1994-v35n3a4 (accessed on 1 May 1994).

24. Ma, X.P. Internal relationship between physical property and micro-pore structure of reservoir. Prog. Explor. Geophys. 2010, 33, 216-219. [CrossRef]

25. Zhang, C.E.; Pan, B.Z.; Liu, Q.R. Reservoir classification evaluation research with combination of reservoir quality factor RQI and clustering algorithm. World Well Logging Technol. 2012, 4, 11-13.

26. Tan, C.Q.; Duan, A.S.; Song, G.S. On the Permeability Models Based on the Petrophysical Facies. World Well Logging Technol. 2001, 25, 287-290. [CrossRef]

27. Coates, G.R.; Xiao, L.Z.; Prammer, M.G. NMR logging: Principles and applications. In Houston: Haliburton Energy Services; Haliburton Energy Services: Houston, TX, USA, 1999.

28. Glover, P.W.; Zadjali, I.I.; Frew, K.A. Permeability prediction from MICP and NMR data using an electrokinetic approach. Geophysics 2006, 71, F49-F60. [CrossRef] 
29. Comisky, J.T.; Newsham, K.; Rushing, J.A.; Blasingame, T.A. A comparative study of capillary-pressure-based empirical models for estimating absolute permeability in tight gas sands. In Proceedings of the SPE Annual Technical Conference and Exhibition, Anaheim, CA, USA, 11-14 November 2007.

30. Dastidar, R.; Sondergeld, C.H.; Rai, C.S. An improved empirical permeability estimator from mercury injection for tight clastic rocks. Petrophysics 2007, 48, 3 .

31. Daigle, H.; Johnson, A. Combining mercury intrusion and nuclear magnetic resonance measurements using percolation theory. Transp. Porous Med. 2016, 111, 669-679. [CrossRef]

32. Huet, C.C.; Rushing, J.A.; Newsham, K.E.; Blasingame, T.A. A modified purcell/burdine model for estimating absolute permeability from mercury-injection capillary pressure data. In Proceedings of the International Petroleum Technology Conference, Doha, Qatar, 21-23 November 2005.

33. Katz, A.J.; Thompson, A.H. Quantitative prediction of permeability in porous rock. Phys. Rev. B 1986, 34, 8179-8181. [CrossRef]

34. Mao, Z.Q.; Xiao, L.; Wang, Z.N.; Jin, Y.; Liu, X.G.; Xie, B. Estimation of permeability by integrating nuclear magnetic resonance (NMR) logs with mercury injection capillary pressure (MICP) data in tight gas sands. Appl. Magn. Reson. 2013, 44, 449-468. [CrossRef]

35. Qiu, Z.; Shi, Z.S.; Dong, D.Z.; Lu, B.; Zhang, C.C.; Zhou, J.; Wang, H.Y.; Xiong, B.; Pang, Z.L.; Guo, H.K. Geological characteristics of source rock and reservoir of tight oil and its accumulation mechanism: A case study of Permian Lucaogou Formation in Jimusar sag, Junggar Basin. Pet. Explor. Dev. 2016, 43, 928-939. [CrossRef]

36. Anovitz, L.M.; Cole, D.R. Characterization and analysis of porosity and pore structures. Rev. Mineral. Geochem. 2015, 80, 61-164. [CrossRef]

37. Pittman, E.D. Relationship of porosity and permeability to various parameters derived from mercury injection-capillary pressure curves for sandstone. AAPG Bull. 1992, 76, 191-198.

38. Fordham, E.J.; Schwartz, L.M.; Venkataramanan, L.; Flaum, M.; Ramakrishnan, T.S. New interpretation methodology based on forward models for magnetic resonance in carbonates. In Proceedings of the SPWLA 40th Annual Logging Symposium, Oslo, Norway, 30 May-3 June 1999.

39. Rezaee, R.; Saeedi, A.; Clennell, B. Tight gas sands permeability estimation from mercury injection capillary pressure and nuclear magnetic resonance data. J. Pet. Sci. Eng. 2012, 88, 92-99. [CrossRef]

40. Zhang, T.F.; Fan, G.X.; Li, Y.W.; Yu, C.F. Pore-throat characterization of tight oilReservoir in the Lucaogou formation, Jimusar sag. CT Theory Appl. 2016, 25, 425-434. [CrossRef]

41. Zhao, P.Q.; Sun, Z.C.; Luo, X.P.; Wang, Z.L.; Mao, Z.Q.; Wu, Y.Z.; Xia, P. Study on the response mechanisms of nuclear magnetic resonance (NMR) log in tight oil reservoirs. Chin. J. Geophys. 2016, 29, 1927-1937. [CrossRef]

(C) 2019 by the authors. Licensee MDPI, Basel, Switzerland. This article is an open access article distributed under the terms and conditions of the Creative Commons Attribution (CC BY) license (http://creativecommons.org/licenses/by/4.0/). 